\title{
Potent restriction of HIV-1 and $\operatorname{SIV}_{\operatorname{mac} 239}$ Replication by African Green Monkey TRIM5a
}

\author{
Lori V Coren, Matthew T Trivett, Sumiti Jain, Victor I Ayala, Gregory Q Del Prete, Claes Ohlen and David E Ott
}

\begin{abstract}
Background: The TRIM5a protein is a principal restriction factor that contributes to an HIV-1 replication block in rhesus macaque $\mathrm{CD}^{+}{ }^{+} \mathrm{T}$ cells by preventing reverse transcription. HIV-1 restriction is induced in human $\mathrm{CD} 4^{+} \mathrm{T}$ cells by expression of rhesus TRIM5a as well as those of other old world monkeys. While TRIM5a restriction has been extensively studied in single-round infection assays, fewer studies have examined restriction after extended viral replication.
\end{abstract}

Results: To examine TRIM5a restriction of replication, we studied the ability of TRIM5a proteins from African green monkey (AgmTRIM5a) and gorilla (gorTRIM5a) to restrict HIV-1 and SIV mac239 replication. These xenogeneic TRIM5a genes were transduced into human Jurkat-CCR5 cells (JR5), which were then exposed to HIV-1 or SIV mac239. In our single-round infection assays, AgmTRIM5a showed a relatively modest 4- to 10-fold restriction of HIV-1 and $\mathrm{SIV}_{\text {mac239, }}$ while gorTRIM5a produced a 2- and 3-fold restriction of HIV-1 and SIV $\mathrm{mac}_{239}$, respectively, consistent with the majority of previously published single-round studies. To assess the impact of these modest effects on infection, we tested restriction in replication systems initiated with either cell-free or cell-to-cell challenges. AgmTRIM5a powerfully restricted both HIV-1 and SIV mac239 replication 14 days after cell-free infection, with a $\geq 3$-log effect. Moreover, expression of AgmTRIM5a restricted HIV-1 and SIV mac239 replication by 2-logs when co-cultured with infected JR5 cells for 12 days. In contrast, neither expression of gorTRIM5a nor rhesus TRIM5a induced significant resistance when co-cultured with infected cells. Follow up experiments showed that the observed differences between replication and infection were not due to assembly defects as xenogeneic TRIM5a expression had no effect on either virion production or specific infectivity.

Conclusions: Our results indicate that AgmTRIM5a has a much greater effect on extended replication than on any single infection event, suggesting that AgmTRIM5a restriction acts cumulatively, building up over many rounds of replication. Furthermore, AgmTRIM5a was able to potently restrict both HIV-1 and SIV replication in a cell-to-cell infection challenge. Thus, AgmTRIM5a is unique among the TRIM5a species tested to date, being able to restrict even at the high multiplicities of infection presented by mixed culture with nonrestrictive infected cells.

Keywords: HIV, SIV, TRIM5a, Restriction factor, Cumulative restriction

\section{Background}

Studying cellular resistance to HIV-1 infection mediated by cellular proteins, i.e. resistance factors, is important for the understanding of viral biology and identifying potential opportunities for AIDS therapeutics [1-10]. These cellular proteins interact with viral partners to block various steps in the retroviral replication cycle, thereby suppressing virus infection and spread [11]. The TRIM5 $\alpha$ restriction factor belongs to the very large tripartite motif

* Correspondence: ottde@mail.nih.gov

AIDS and Cancer Virus Program, Leidos Biomedical Research Inc., Frederick National Laboratory for Cancer Research, PO Box B, Frederick, MD 21702, USA
(TRIM) family of proteins [12,13], and is a well-studied HIV-1 resistance factor [14]. In the early 1990's, a resistance to HIV-1 infection of rhesus macaque cells was observed, manifested as a post-entry block to reverse transcription that mapped to a few viral proteins, most notably Gag [15-17]. Over a decade later, the TRIM5 $\alpha$ cytoplasmic body protein, was identified as a principal restriction factor for HIV-1 in rhesus macaque $\mathrm{CD}^{+} \mathrm{T}$ cells which binds the capsid protein (CA) in capsid cores after virus entry, thereby, interfering with early reverse transcription $[18,19]$. In many cases viral restriction in normally permissive cells can be produced by ectopic expression of 
TRIM5 $\alpha$ from other species, i.e., xenogeneic expression, producing a somewhat complicated pattern of restriction in a variety of virus/TRIM5 $\alpha$ pairings [18,20-26].

As with all TRIM family members [12,13], TRIM $5 \alpha$ contains a really interesting new gene (RING) finger domain with an E3 ubiquitin ligase activity, a B-box zinc finger, a coiled-coil domain as well as a fourth noncanonical B30.2(SPRY) domain [12,13]. The basis for the differential xenogeneic restricting capabilities of TRIM $5 \alpha$ proteins lies in the RING and B30.2(SPRY) domains. The B30.2(SPRY) region binds capsid and is necessary, but not sufficient for restriction [9,18,27-30]. A single amino acid difference in the RING finger is critical for the restriction of $\operatorname{SIV}_{\text {mac }}$ by tantalus African green monkey TRIM5 $\alpha$ (AgmTRIM5 $\alpha$ ) [31,32], but not other TRIM5 $\alpha /$ virus combinations $[18,29,33,34]$. Thus, the contributions of the RING domain across the different TRIM $5 \alpha /$ virus combinations are quite complicated and, in some cases, unclear. Also, the exact nature of the block is clouded by data supporting the possibility of multiple mechanisms of interference with the post-entry infection process that act between early reverse transcription [18] and nuclear entry/integration of the cDNA $[35,36]$.

TRIM5 $\alpha$ restricts infection inside the cell by binding the CA-coated capsid core structure soon after entry [37]. The capsid core contains all of the elements needed for infection, the genomic RNA bound by nucleocapsid protein, reverse transcriptase, and integrase, all encased in a highly structured conical CA protein shell poised to carry out the infection process [38]. Current models propose infection proceeding, post-entry, by the CA core rearranging and partially uncoating in a controlled manner at the appropriate time to allow for reverse transcription. Therefore, CA-CA interactions in the capsid core need to be finely balanced, strong enough to maintain core structure in virio, yet weak enough to appropriately uncoat during the infection process inside the cell. Indeed, virion infectivity requires the correct conical capsid core structure [39]: CA mutations that either stabilize or destabilize the capsid core have drastic effects on infectivity, reflecting the fragile balance of core stability [40].

The exact mechanism for TRIM5 $\alpha$ restriction is not completely understood, but it clearly involves TRIM $5 \alpha$ binding the CA shell in a highly cooperative manner, which results in the proteins forming an ordered cage around the core $[41,42]$. The current data supports two models for the mechanism of TRIM5 $\alpha$ restriction. In one model, the TRIM5 $\alpha$ cage disrupts the normal, presumably ordered, rearrangement and uncoating process, thereby prematurely disintegrating the CA shell [35,43-45]. Alternatively, the RING finger E3 ubiquitin ligase activity of TRIM $5 \alpha$ could be ubiquitinated itself as well as CA after complex formation, marking both TRIM5 $\alpha$ and the CA core for destruction by the proteasome [32,36]. Indeed, TRIM5 $\alpha$ and viral components are associated with cytoplasmic bodies that accumulate upon proteasome inhibition [46], although CA ubiquitination by TRIM5 $\alpha$ has not yet been observed. It is important to note that these two models are not mutually exclusive and there is strong evidence that different TRIM $5 \alpha /$ virus combinations could use different mechanisms (please see references in $[32,36,42]$ ). For instance, HIV-1 restriction by rhesus macaque TRIM $5 \alpha$ (rhTRIM5 $\alpha$ ) does not require the RING E3 ubiquitin ligase activity [35], while this function is required for restriction of SIV $_{\text {mac }}$ by AgmTRIM5 $\alpha$ [32]. Finally, TRIM5 $\alpha$ acts as a pattern recognition receptor that senses TRIM5 $\alpha$-capsid core complexes, which then activates innate immune signaling [47]. While its exact contribution to restriction is not clear, this induction of signaling is required for TRIM5 $\alpha$ restriction in some experimental contexts [47].

Normally, human TRIM $5 \alpha$ restricts only a few retroviruses, being ineffective against $\mathrm{HIV}-1, \mathrm{SIV}_{\mathrm{mac}}$ and $\operatorname{SIV}_{\text {Agm }}[22,24,25]$, although transduction of a mutant human TRIM5 $\alpha$ with an extended half-life can induce HIV-1 restriction in human cells [10]. In contrast, single-round infectivity assays with pseudotyped defective viruses or viral vectors have found that rhTRIM $5 \alpha$ strongly ( $>70-95 \%)$ restricts HIV-1 infection, while AgmTRIM5 $\alpha$ weakly $(\sim 60 \%)$ restricts SIV $_{\text {mac }}$, with gorilla TRIM5 $\alpha$ (gorTRIM5 $\alpha$ ) having a stronger effect $(\sim 90 \%)$ [22]. Despite a large body of infection experiments, only a few studies have examined TRIM5 $\alpha$ restriction using wildtype viruses in cell-free replication assays $[8,10,18,30,48,49]$.

TRIM5 $\alpha$ restriction provides a potent block to HIV-1 infection of rhesus macaque $\mathrm{CD}^{+} \mathrm{T}$ cells that, along with other resistance factors, make them essentially unable to support a spreading infection $[17,23,48,50]$. Because of this effect, xenogeneic expression of rhTRIM $5 \alpha$ by gene transfer has been proposed as a way to protect human $\mathrm{CD}^{+} \mathrm{T}$ cells from HIV-1 [1,3-5]. Despite its promise, preliminary work indicated that xenogeneic expression of rhTRIM5 $\alpha$ protected primary human $\mathrm{CD} 4^{+}$ T cells only under certain circumstances [48], most notably when all of the cells expressed the restricting protein. rhTRIM5 $\alpha$ failed to protect cells from HIV-1 exposure by cell-to-cell contact with infected cells without rhTRIM5 $\alpha$ [48]. To better investigate the basis for TRIM5 $\alpha$ restriction of replication and extend TRIM5 $\alpha-$ mediated restriction studies to the SIV/rhesus macaque model system, we chose to examine two lesser-studied TRIM5 $\alpha$ proteins that were previously found to restrict SIV $_{\text {mac }}$, AgmTRIM5 $\alpha$ and gorTRIM5 $\alpha$, for their ability to restrict either HIV-1 or SIV $_{\text {mac239 }}$ replication in a human $\mathrm{CD}_{4}{ }^{+} \mathrm{T}$-cell line. Our results showed that, despite a relatively weak effect against HIV-1 and $\mathrm{SIV}_{\text {mac }}$ viruses and pseudotyped vectors in short term and single-round infection assays, AgmTRIM5 $\alpha$ expression induced a high 
level of restriction to both HIV-1 and SIV replication in a human $\mathrm{CD}^{+} \mathrm{T}$-cell line in both cell-free and cell-tocell challenge systems.

\section{Results}

To study TRIM5 $\alpha$ restriction, we produced murine retroviral vectors that express $\mathrm{N}$-terminally hemagglutinin epitope (HA) tagged TRIM5 $\alpha$ proteins from either tantalus African green monkey (SMS-hAgmT) or gorilla (SMShgorT) [21,22] along with the GFP and the puromycin resistance genes. Because, N-terminal HA tags might affect the function of TRIM $5 \alpha$ [20], we also produced two vectors (Babe-AgmT and Babe-gorT) that express native TRIM $5 \alpha$ proteins and the puromycin-resistance gene. JR5 cells (human Jurkat $\mathrm{CD}_{4}^{+} \mathrm{T}$ cells transduced with the CCR5 gene) were transduced with pseudotyped vectors and puromycin resistant cells were selected, producing the hAgmT, hgorT, AgmT, and gorT cell lines. To measure the expression of ecotopic TRIM5 $\alpha$ in these JR5 cell lines, we analyzed cell lysates by immunoblotting using the quantitative two-color near infrared fluorescence (NIr) LICOR system with the 3F1-1-9 monoclonal antibody specific for a primate-conserved rhTRIM5 $\alpha$ epitope and an actin antibody as a cell lysate loading control. The results (Figure 1A) showed that, in addition to the endogenous human TRIM5 $\alpha$ band at $56 \mathrm{kDa}$ (present in the untransduced JR5 cell lysate), there were bands at 59 and $57 \mathrm{kDa}$ in the hAgmT and hgorT lysates, respectively, corresponding to the expected molecular masses (TRIM5 $\alpha$ with the HA-tag) of the hAgmTRIM5 $\alpha$ and hgorTRIM5 $\alpha$ proteins. Similarly, the AgmT cell lysates contained bands at $56 \mathrm{kDa}$ and $58 \mathrm{kDa}$, consistent with human and AgmTRIM5 $\alpha$ proteins, respectively. In contrast, the gorT line contained only one band at $56 \mathrm{kDa}$, yet with a greater intensity relative to the bands in the other samples (Figure 1A). Due to their nearly identical molecular mass, ectopic gorilla and endogenous human TRIM5 $\alpha$ proteins co-migrate. Measurement of the fluorescence intensities of both the xenogeneic and endogenous TRIM $5 \alpha$ bands and normalization by actin band signal revealed that the range of ectopic TRIM5 $\alpha$ expression was close to normal physiological levels (Figure 1B), only 1 - to 2 -fold over that of endogenous human TRIM5 $\alpha$ among the different transduced cell lines.

\section{Xenogeneic TRIM5a expression modestly restricts HIV-1 and SIV single-round infection}

The magnitude of TRIM5 $\alpha$ restriction has been well established by challenging cells with viral vectors or defective GFP-expressing viruses [18,20-26]. To confirm the viral inhibition effect of xenogeneic TRIM5 $\alpha$ on single-round infection in our cell lines, the AgmT and gorT cells were exposed to either HIV-1 or SIV-based lentiviral vectors that express GFP. Flow cytometry for
GFP fluorescence revealed that AgmT cells exhibited somewhat more resistance to HIV vector transduction than the gorT cells, with a 4-fold compared to a 3-fold resistance to infection, respectively (Figure 1C). These results generally agree with prior published studies. To examine infection in a more physiological system, the xenogeneic TRIM5 $\alpha$-expressing cells were infected with either HIV-1 or SIV mac239 $_{2}$ and Gag-positive cells were measured 40-h post-infection by intracellular flow cytometry with CA antibodies. To control for non-specific virion binding, the numbers of Gag-positive cells were adjusted for the background present in the heatinactivated virus. The results were similar to those of the vector-derived data: the infection of AgmT cells was 90\% lower for both viruses, and gorT cells demonstrated a more modest reduction of infection, approximately $70 \%$ (Figure 1D).

For comparison to the more extensively studied rhesus macaque system, we examined the effect of xenogeneic rhTRIM5 $\alpha$ in our short-term infection assay. JR5 were transduced with the Babe-rhT vector, which expresses rhTRIM $5 \alpha$ and puromycin acetyltransferase, and selected with puromycin to produce the rhT cell line. Immunoblot analysis of rhT lysates revealed only a single, more intense TRIM $5 \alpha$-sized band due to the close molecular masses of rhTRIM5 $\alpha$ and its human counterpart (Figure 1A). Measurement of the bands found a 6-fold increase in the TRIM $5 \alpha$ over that of the JR5 controls (Figure 1B), a higher level of exogenous expression that the other JR5/TRIM5 $\alpha$ cell lines. Consistent with prior results, the rhTRIM5 $\alpha$-expressing cells reduced HIV-1 infectivity by an amount similar to that of the AgmTRIM5 $\alpha$ proteins in the short term assay and did not significantly affect SIV infection, as expected (Figure 1D). Modest restriction was also observed by assaying HIV-1 and SIV $_{\text {mac239 }}$ in Agm- and gorTRIM5 $\alpha$-expressing TZMbl cells (data not shown). Thus, in our systems, xenogeneic expression of these three TRIM5 $\alpha$ proteins results in a modest level of restriction in single-round/ short-term assays and recapitulates most prior studies of Agm- and rhTRIM5 $\alpha[9,18,21-24,26-30]$.

\section{Strong AgmTRIM5a replication restriction after a cell-free challenge}

To determine the effect of these TRIM5 $\alpha$ proteins on extended replication, JR5, hAgmT, AgmT, hgorT, and gorT cells were infected with cell-free stocks of HIV-1 $1_{\text {NL4-3 }}$ or SIV $_{\text {mac239 }}$ from freshly prepared transfection supernatants at 10 -fold dilutions. Cells were cultured for 14 days with periodic fluid changes before supernatants were harvested and analyzed for the presence of virions by CA NIr immunoblot (Figure 2A). The HIV-1 cell-free challenge assays showed that the JR5 cells had detectable p $24^{\mathrm{CA}}$ bands out to the $10^{-4}$ inoculum dilution, with no detectable signal in 


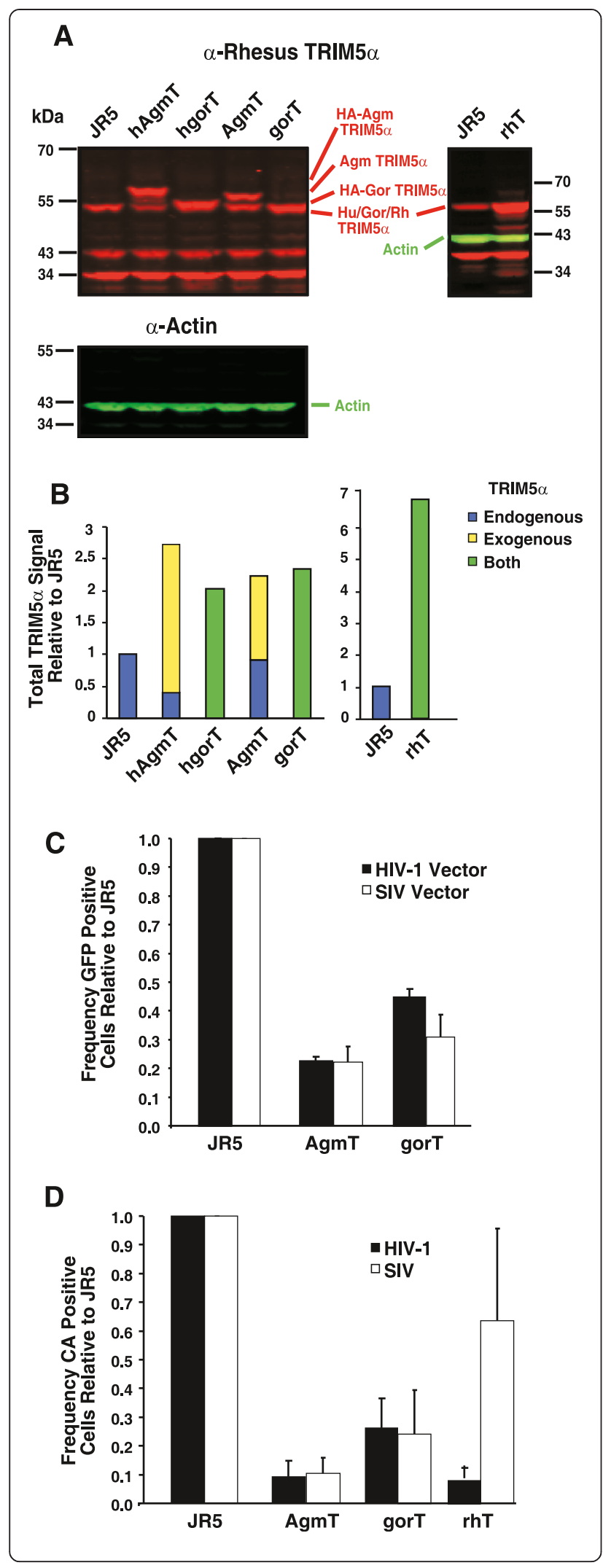

Figure 1 Ecotopic expression in JR5 cells and infection assays. (A). A NIr immunoblot of cell lysate samples is presented with TRIM5a signal in red and actin in green. Samples are identified above their respective lanes, with molecular mass standard sizes and band identities displayed at the margins. (B). A graph of fluorescent immunoblot signal intensities in the NIr blot relative to those of the untransduced JR5 cells is presented with the amount of endogenous, human TRIM5a-colored blue, xenogeneic TRIM5a colored yellow, and co-migrating TRIM5a proteins colored green. (C) A graph of flow cytometry analysis results for GFP signal from single-round infectivity assays (MOI $=0.05)$ using $\mathrm{HIV}^{-1}$ NL4-3 $_{\text {and }}$ and

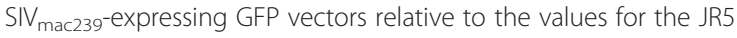
positive controls is presented. (D) A graph of results of flow cytometry analysis for intracellular CA 40-h post infection with either $\mathrm{HIV}^{-1}$ NL4-3 $_{\text {or }}$ $\mathrm{SIV}_{\text {mac239 }}(\mathrm{MOI}=0.05)$ is presented. Graphs $C$ and $\mathrm{D}$ are averages of three independent experiments and error bars indicate standard deviation. Statistical of the experimental versus the control values for the data in both panels $\mathbf{C}$ and $\mathbf{D}$ generated $p$-values of $<0.012$ for all pairs except for the rhTRIM5a/SIV sample, $p=0.37$.

the $10^{-5}$ dilution, indicating an end-point titer of $\geq 10^{4}$ to $<10^{5}$. In contrast, supernatants from the hAgmT and AgmT cultures had a slight $\mathrm{p} 24^{\mathrm{CA}}$ signal in the neat infection sample and no detectable signal in any of those from virus dilution cultures (Figure 2A), indicating a strong level of restriction induced by both versions of TRIM $5 \alpha, \geq 10^{3} /<10^{4}$ fold. In contrast, the hgorT and gorT cultures had essentially the same levels of $\mathrm{p} 24^{\mathrm{CA}}$ in the challenge dilutions as the JR5 positive controls, with intense $\mathrm{p} 24^{\mathrm{CA}}$ bands in the neat through the $10^{4}$ dilution samples, indicating at least levels of replication similar to those of JR5 (Figure 2A). This is expected given the high level of conservation of between human and gorilla TRIM5 $\alpha$ genes [22].

A NIr immunoblot of virus samples from JR5 cultures infected with the SIV mac239 $_{\text {dilution series revealed that }}$ p28 ${ }^{\mathrm{CA}}$ signals were detectable out to the $10^{-3}$ dilution (Figure 2A), in part reflecting a lower susceptibility of JR5 cells to infection by SIV $_{\text {mac239 }}$ than to HIV-1, a phenomenon that we observe in most human cell lines (D. Ott unpublished data). Similar to the HIV-1 results, both hAgmT and AgmT cells showed a high level of resistance with no $228^{\mathrm{CA}}$ signal detectable in any of the supernatants from infected cells (Figure 2A), indicating a resistance of $\geq 10^{3}$. The cell-free SIV-challenged gorT cells had little $\mathrm{p} 28^{\mathrm{CA}}$ signal at the $10^{-3}$ dilution compared to that of the JR5 control band while the hgorT had little difference in intensity from the control at the $10^{-3}$ dilution (Figure 2A), indicating, at most, a 10-fold level of restriction induced by gorTRIM $5 \alpha$, considerably lower than that of AgmTRIM5 $\alpha$ transduced cells.

Others have noted that overexpression of TRIM $5 \alpha$ to high levels ( $>50$-fold) $[20,51,52]$ or increasing the stability of TRIM5 $\alpha$ [10] can result in restriction-like effects in single-round experiments. While the amount of total TRIM5 $\alpha$ expression, both endogenous and exogneous, 


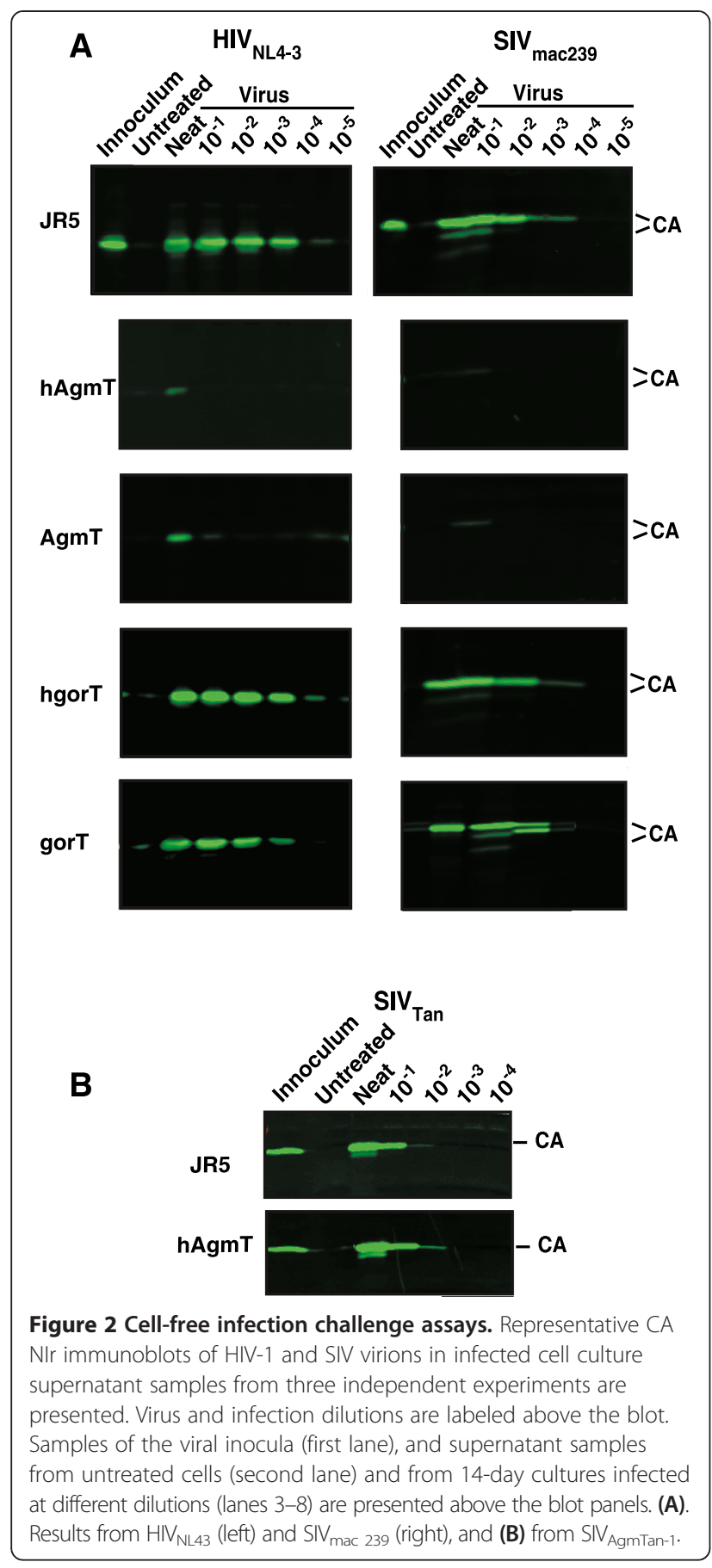

in the hAgmT and AgmT cells was elevated only 2-to2.5 -fold in the transduced cell lines, it is possible that these levels of over-expression might still cause nonspecific restriction. To address this possibility, we examined both JR5 and hAgmT cells in our replication assay with $\mathrm{SIV}_{\mathrm{AgmTan}-1}$, a cognate virus for AgmTRIM5 $\alpha$. The results showed no evidence of restriction in the hAgmT cells, with nearly similar amounts $\mathrm{p} 28^{\mathrm{CA}}$ signal detected in the neat and $10^{-1}$ dilution samples and a slight signal detected in the $10^{-2}$ dilution sample (Figure 2B). Thus, the restriction patterns observed in these experiments are not an artifact of TRIM $5 \alpha$ overexpression and are consistent with specific AgmTRIM5 $\alpha$-mediated restric-

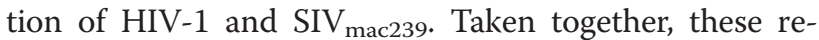
sults indicate that AgmTRIM5 $\alpha$ specifically restricts HIV-1 and SIV, while gorTRIM5 $\alpha$ fails to restrict HIV-1 and only weakly restricts SIV.

\section{AgmTRIM5a restricts when challenged with infected cells}

The cell-free virus challenge results presented above demonstrate restriction in a culture in which all of the cells express xenogeneic TRIM5 $\alpha$. However, cell-to-cell infection, i.e., extracellular virions being transferred across cell-cell contacts, is up to 1000 -fold more efficient than a cell-free challenge, [48,53-61]. To test restriction in our xenogeneic TRIM $5 \alpha$-expressing cells by this more stringent challenge, AgmT and gorT cells were cultured with either HIV-1 or SIV-infected JR5G cells, JR5 cells that express GFP to differentiate the infected challenge cells from the TRIM5 $\alpha$-transduced target cells (Figures $3 \mathrm{~A}$ and $4 \mathrm{~A}$ ), at increasing 10 -fold ratios, ranging from 50 - to- $5 \times 10^{5}$ cells. After 12-days, the xenogeneic TRIM $5 \alpha$-expressing cells in the mixed cultures were analyzed for infection by intracellular Gag flow cytometry using CA antibodies and gating on GFP negative cells (Figure 3A).

The intracellular p24 ${ }^{\mathrm{CA}}$ staining for Gag in the JR5 targets revealed the presence of $30 \%$ to $70 \%$ HIV-infected JR5 cells in all of the mixed cultures (Figure 3B). Interestingly, the cultures initiated with 500 JR5G-infected cells contained the highest level of infected JR5 targets, 70\%, while the $5 \times 10^{5}$ cell culture contained only $30 \%$ (data not shown), apparently due to cytopathology induced by the presence of HIV-1 over the 12-day testing period. In contrast to the JR5 infection results, the AgmT target cells had either background or considerably reduced levels of Gag staining at the 50- and 500-infected-cell challenge levels, $0.3 \%$ and $1 \%$ respectively (Figure $3 \mathrm{~B}$ ). The levels of HIV-infected gorT in the various mixed culture ratios mirrored the JR5 cultures, with only a minor reduction of Gag-positive cells in the 50-cell culture (44\%), compared to the Gag-positive cells in the JR5 culture (55\%). Thus, gorTRIM $5 \alpha$-expressing cells demonstrated little, if any, cell-to-cell restriction, similar to the cell-free challenge results. In contrast, cells expressing AgmTRIM5 $\alpha$ exhibited a $10^{2}$ restrictive phenotype for HIV-1 replication.

Prior results reported by Richardson et al. expressing rhTRIM5 $\alpha$ in primary human $\mathrm{CD}^{+} \mathrm{T}$ cells observed that restriction protected transduced cells from HIV-1, but failed to do so when untransduced cells were also present at the initial cell-free inoculation. Additional experiments confirmed that this was due to cell-to-cell transfer of HIV-1 from the infected xenogeneic TRIM5 $\alpha$ 


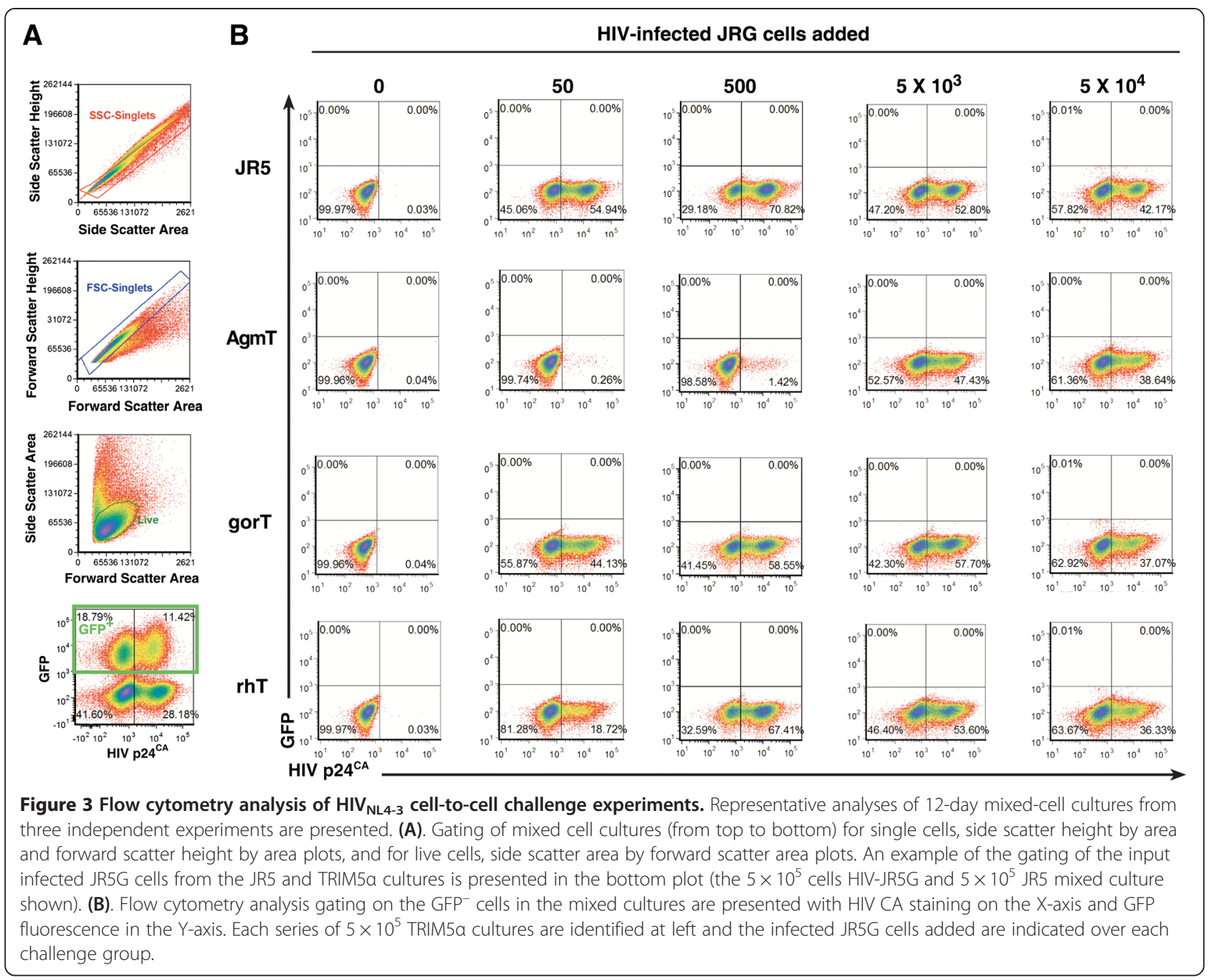

negative cells to the xenogeneic TRIM5 $\alpha$ positive cells [48]. To determine whether rhTRIM5 $\alpha$ could restrict HIV-1 in our assay, which is similar to the Richardson assay, we tested rhT cells in our cell-to-cell challenge assay. In contrast to the single-round assay, rhT cells showed only marginal HIV-1 restriction at the 50-cell challenge, $19 \%$ infected cells, compared to the JR5 control with 55\% infected cells present, and essentially the same frequency of infected cells in the 500-cell cultures (Figure 3B). Thus, similar to the results reported by Richardson et al., our results showed that rhTRIM5 $\alpha$ fails to restrict HIV-1 infection in this high multiplicity of infection (MOI) cell-to-cell setting.

Flow cytometry of the SIV-mixed cultures found that, as in our cell-free experiments, the extent of the SIV $_{\text {mac239 }}$ infection of the target JR5 cells, while robust, was less than the extent of HIV-1 infection: SIV infection was clearly evident at the 500-cell challenge, with $30 \%$ of the cells infected (Figure 4B). The AgmT results were quite similar to those of the HIV-1 assay: the 500-cell challenge had background staining and the $5 \times 10^{3}$-cell challenge culture contained considerably reduced levels of infected cells, 1\% frequency, versus 38\% for the JR5 control (Figure 4B). Some restriction was even evident at the $5 \times 10^{4}$-cell challenge with $27 \%$ of the AgmT cells containing Gag compared to $43 \%$ of the JR5 cells. As seen in the cell-free infection experiments, the gorT cells displayed lower levels of $\mathrm{SIV}_{\text {mac239 }}$ restriction than AgmT cells, reducing the number of infected cells in the 500-cell mixed culture to $5 \%$, as compared to a $30 \%$ frequency for the JR5 control and a $27 \%$ to $38 \%$ presence of infected cells in the $5 \times 10^{3}$ cell challenge culture. As expected, rhT cells exhibited only slightly fewer infected cells than the JR5 controls (Figure 4). Taken together, these data show that AgmTRIM5 $\alpha$ potently restricts both HIV-1 and SIV mac239, even in this rigorous cell-to-cell challenge, while, as predicted by the cell-free assays, gorTRIM $5 \alpha$ only modestly restricts SIV $_{\text {MAC239. }}$ 


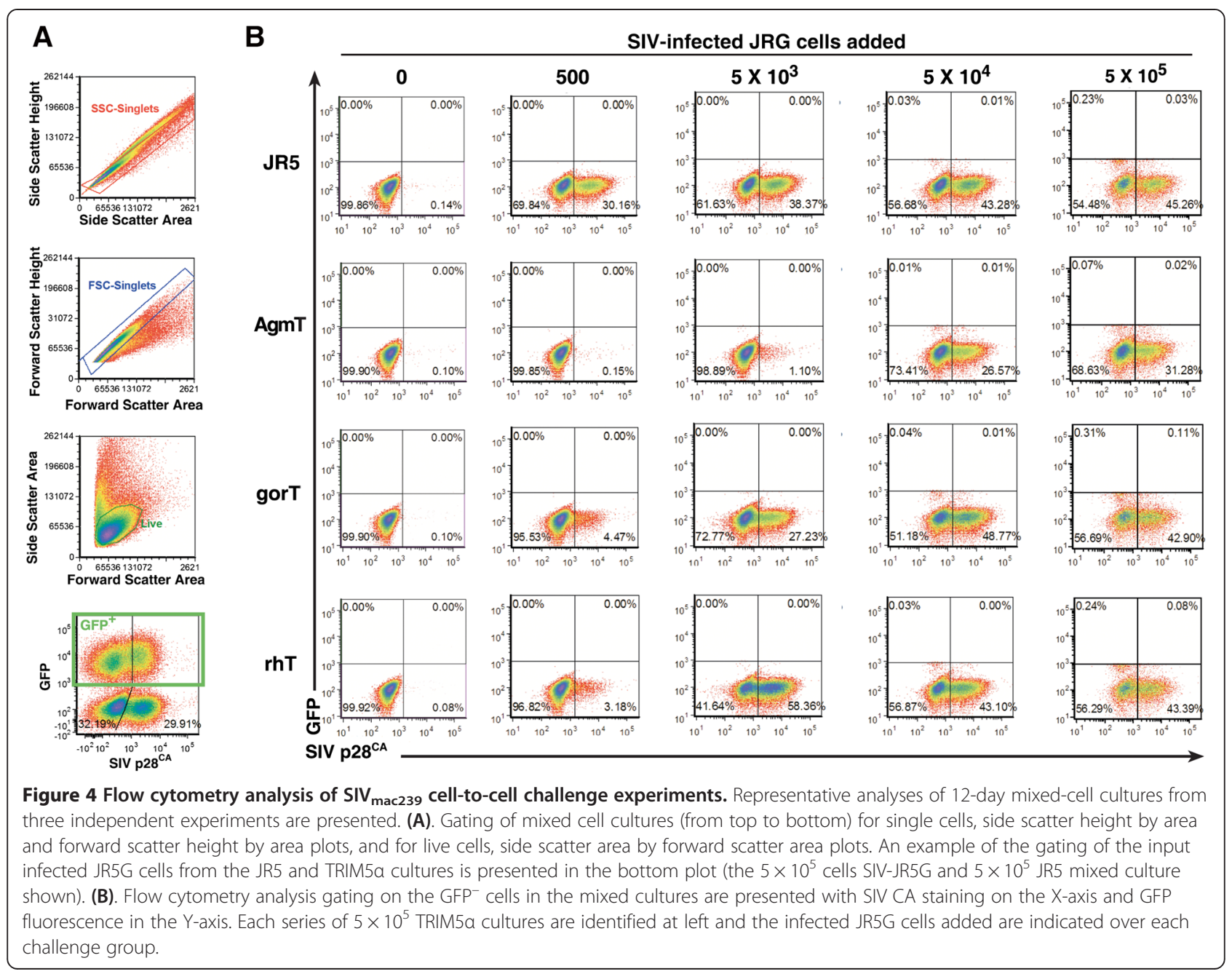

\section{AgmTRIM5a replication restriction effect is not due to lower virus production}

The strength of AgmTRIM5 $\alpha$ restriction of HIV-1 and SIV in both the cell-free and, especially, the cell-to-cell replication assays is unexpected since its influence on single-round infection was fairly modest. One formal possibility for the discrepancy between the replication and single-round infection results is that the expression of xenogeneic TRIM5 $\alpha$ in our cells decreases virus production. Previous reports indicated that xenogeneic expression of TRIM $5 \alpha$ can reduce the amount of infectious virions produced from cells $[51,62]$, though these observations remain controversial $[20,52,63]$. To formally rule out lower virion production from infected cells by our xenogeneic TRIM $5 \alpha$ expression approach as a possible mechanism for our results, we investigated whether the expression of AgmTRIM5 $\alpha$ or gorTRIM5 $\alpha$ reduces virus release from infected cells. We transduced two human $\mathrm{CD}_{4}{ }^{+} \mathrm{T}$-cell lines, Clone 4 [64] (cloned from HIV-infected H9 cells) and E11S [65] (cloned from SIV- infected HuT 78 cells), which produce high constitutive levels of HIV-1 or SIV, respectively with the SMShAgmT or SMS-hgorT vectors. Transductants were selected for puromycin resistance and confirmed by GFP fluorescence, producing the Clone 4 lines Cl4/hAgmT and Cl4/hgorT and the E11S lines, E11S/hAgmT and E11S/hgorT. Quantitative NIr-immunoblot analysis of Clone 4 and E11S transductant cell lysates revealed that exogenous TRIM5 $\alpha$ was expressed at least 2 - to 5 -fold more than the endogenous human protein (Figure $5 \mathrm{~B}$ ), higher than the 1 - to 2 -fold level observed in the JR5 transductants (Figure 1B).

The production of virions from Clone 4 and E11S and their xenogeneic TRIM5 $\alpha$ transductants was measured by isolating virions and cells after a $6-\mathrm{h}$ incubation and analyzing sample lysates by quantitative NIr immunoblotting with CA antibodies. From these data, the release rate was calculated as the amount of CA fluorescent signal in the supernatant divided by the total signal detected, i.e. that amount present in both the virions and 


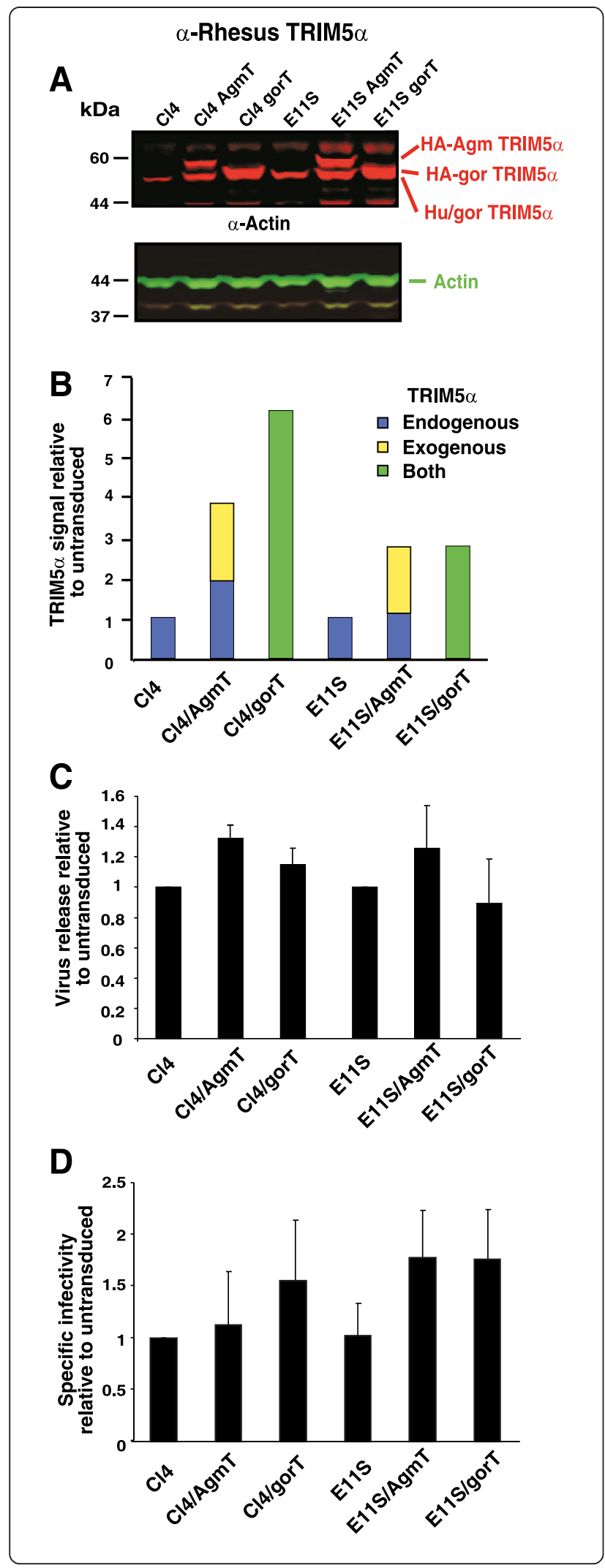

Figure 5 Ectopic expression of TRIM5a in Clone 4 and E11S cells virion production, and infection assays. (A). Nlr immunoblot of cell lysate samples, with TRIM5a signal in red and actin in green are presented. Samples are identified above their respective lanes. Molecular mass standard sizes are displayed at left and band identities at right. (B). Graph of fluorescent immunoblot signal intensities in the NIr blot relative to those in the untransduced Clone 4 or E11S cells are presented with the amount of endogenous, human TRIM5a-colored blue, xenogeneic TRIM5a colored yellow, and co-migrating TRIM5a proteins colored green. (C). Graph of relative virus release (virus in supernatant/virus in cells and supernatant at 6 h) is presented. (D). A graph of relative virus-specific infectivity (virus infectivity after a 6-h collection period normalized by CA signal). Graphs shown in (C) and (D) represent averages of three independent experiments, and error bars indicate standard deviation.

cells. The blots showed little difference in the production of virions from untransduced and transduced cell lines (Figure 5B). Comparing calculations from three independent experiments showed no significant differences in release between the untransduced and TRIM5 $\alpha$ expressing cell lines. Taken together, these data indicate that virion production is not reduced by xenogeneic TRIM5 $\alpha$ transduction and thus is not a factor in the increased potency of AgmTRIM5 $\alpha$ restriction of replication.

\section{Xenogeneic TRIM5a expression has no effect on infectious virion production}

Even though release is normal, it is possible that the virus produced from our xenogeneic TRIM $5 \alpha$ transductants is less infectious than the virus produced from the untransduced cells because of a subtle defect in assembly or maturation. To examine this possibility, the specific infectivity of the virions produced by the Clone 4 and E11S cell lines was measured by the Tat-complementation TZMbl beta-galactosidase focus-forming assay and normalized by the amount of CA in the medium as measured by NIr immunoblot quantitation to calculate specific infectivity of each sample. The results showed that the expression of xenogeneic TRIM $5 \alpha$ had no measurable effect on the specific infectivity of the virions produced from cells (Figure 5C). This finding, together with the release data, formally rule out late replication defects as the reason for the potency of AgmTRIM5 $\alpha$ replication restriction.

\section{Discussion}

Our results identify TRIM5 $\alpha$ from tantalus African green monkey as an effective restriction factor of HIV-1 and SIV replication in $\mathrm{CD} 4^{+} \mathrm{T}$ cells, producing very potent restriction of both HIV-1 and SIV replication, approximately $\geq 10^{-3}$ in the cell-free challenge and $\geq 10^{-2}$ in the more rigorous infected cell challenge system. The ability of AgmTRIM5 $\alpha$ to restrict in the context of a cell-to-cell challenge is remarkable considering that this 
mode of infection is up to 1000 -fold more efficient than the cell-free infection challenge [48,55-61]. In comparison, rhTRIM $5 \alpha$ fails to restrict HIV- 1 replication in our cell-to-cell challenge assay, even though it exhibits essentially equivalent levels of restriction in our short term infection assay as AgmTRIM5 $\alpha$. Furthermore, as discussed above, primary human $\mathrm{CD} 4^{+} \mathrm{T}$ cells transduced with rhTRIM5 $\alpha$ or stabilized human TRIM5 $\alpha$ genes restrict HIV-1 replication, yet fail to do so in cell-to-cell contact with untransduced infected cells $[10,48]$, conditions similar to our cell-to-cell challenge. Similarly, Ohkura et al. found that $\mathrm{N}$-tropic murine leukemia virus produced restriction resistant mutants in target cells expressing either human or rhesus TRIM5 $\alpha$ only when co-cultured with unmodifed cells, indicating a low level of infection in the mixed cultures that was absent with the modified cells alone $[66,67]$. Therefore, AgmTRIM5 $\alpha$ is unique among TRIM5 $\alpha$ proteins studied to date in that it can restrict both HIV-1 and SIV in the severe test afforded by the cell-to-cell challenge in the presence infected non-expressing cells.

It is important to note that after the initial challenge, our cell-free experiments develop a cell-to-cell infection component. After the inoculum is absorbed, the first generation of productively infected cells can initiate the next round of replication by both cell-free and cell-to-cell infection. Because all of the cells express AgmTRIM5 $\alpha$ in the cell-free assay, the initial levels of infected cells are low, thus limiting the opportunity for cell-to-cell transmission. It is important to consider that TRIM $5 \alpha$-mediated restriction is saturable, resistance being overcome by the presence of enough capsid cores to bind and sequester the xenogeneic TRIM5 $\alpha$ and neutralize restriction. When every target cell in a culture expresses AgmTRIM5 $\alpha$ enough virus needs to enter the cells to saturate the xenogeneic TRIM $5 \alpha$. Since the amount of virions produced from the initial infection is low in the presence of AgmTRIM5 $\alpha$, the resulting MOI, either cell-free or cell-to-cell, generated by the cells infected in the second round is insufficient to saturate TRIM5 $\alpha$ in many cells and fails to support spread of infected cells in the subsequent rounds of replication. In contrast, our cell-to-cell experiments initially have infected JR5G cells, thus provide a stronger challenge to restriction which more readily overwhelms the resistance in AgmTRIM5 $\alpha$-expressing targets, resulting in a lower, yet still considerable, level of restriction.

The nature of TRIM5 $\alpha$ restriction also can explain the counter-intuitive relationship between the single-round infection and replication assays. In most cases of retroviral inhibition by other resistance factors or anti-viral compounds, the decrease in infectivity follows linear kinetics: the level of inhibition is directly proportional to that of the agent/defect. In contrast, the suppression of TRIM5 $\alpha$ restriction exhibits multi-hit kinetics: many intact capsid cores need to enter the cell to saturate the cooperatively binding TRIM $5 \alpha$, before the strong anti-viral block to infection is removed. Thus, capsid core-mediated saturation of TRIM $5 \alpha$ restriction follows logarithmic kinetics with a strong, nearly absolute, block at lower MOIs that initially has small marginal reductions in restriction with increasing virus exposure. Because restriction requires cooperative TRIM5 $\alpha$ binding to intact capsid cores $[41,42,68]$, as the amount of restricting TRIM5 $\alpha$ in the cell is reduced by binding to the cores, incremental dosages of capsid cores have larger marginal effects on saturating TRIM5 $\alpha$ restriction [41,68-71]. After TRIM5 $\alpha$ is saturated, infection occurs without restriction. Therefore, subsequent rounds of infection initially face a near-absolute block mediated by TRIM5 $\alpha$ restriction which requires enough capsid cores to overcome this restriction hurdle and productively infect cells. In this way, a modest block has a cumulative effect, being amplified by the amount of virus needed to surmount the restriction hurdle at each round of replication. Indeed, Ohkura et al. observed nearly absolute restriction to replication in an $\mathrm{N}$-tropic murine leukemia virus/rhTRIM $5 \alpha$ system that was negligible at a 10 -fold higher MOI, consistent with this restriction hurdle model [66]. In addition to the inherent nature of TRIM5 $\alpha$ restriction, other cellular and viral factors can come into play. For instance, a spreading infection can also be limited by virus-induced cell death and the spontaneous decay of virions in the cell culture supernatant $[72,73]$, both of which remove sources of infection.

Given this cumulative restriction hurdle model, the failure of gorTRIM $5 \alpha$ to effectively restrict SIV replication in either assay can be explained by the lower efficacy of gorTRIM $5 \alpha$ restriction observed in the single-round and short term infection assays. For gorTRIM $5 \alpha$, the restrictive barrier to infection, although reducing SIV singleround infection by $70 \%$, does not appear to present a high enough of a restriction hurdle to have a cumulative effect for replication.

Taken together, AgmTRIM5 $\alpha$ appears to be superior to other TRIM5 $\alpha$ in restricting both HIV-1 and SIV when expressed at near-physiological levels. Despite observing inhibition of infection that was comparable to that of AgmTRIM5 $\alpha$ in a single-round infection assay, rhTRIM5 $\alpha$ failed to restrict in our cell-to-cell assay. While these two proteins are fairly homologous, AgmTRIM5 $\alpha$ contains a 37-amino acid region with a unique 20-amino acid duplication in the B30.2(SPRY) domain which forms the basis of $\operatorname{SIV}_{\text {mac }}$ restriction $[22,30]$ and is likely to be a factor for its superior potency against HIV-1 replication. Additionally, the basic restriction mechanism for AgmTRIM5 $\alpha$ restriction appears to have different requirements than those of rhTRIM $5 \alpha$, notably E3 ubiquitin ligase activity [32]. With its B30.2(SPRY) 
duplication, AgmTRIM5 $\alpha$ is unique among primate TRIM5 $\alpha$ proteins [24], and this feature may be the reason for the exceptional restriction of cell-to-cell infection. Fine mapping of the critical residues in this region of B30.2(SPRY) responsible for the elite restriction by AgmTRIM5 $\alpha$ and their interactions with HIV-1 capsid should yield important information about the mechanism for effective TRIM $5 \alpha$ restriction.

The restrictive properties of TRIM $5 \alpha$ have been proposed as the basis of anti-viral therapies $[1,2,8,10,49]$. Our results showing effective AgmTRIM5 $\alpha$-mediated restriction of HIV-1 and $\mathrm{SIV}_{\text {mac239 }}$ in $\mathrm{CD}^{+}{ }^{+} \mathrm{T}$ cells are consistent with the use of the TRIM $5 \alpha$ restriction mechanism as an anti-HIV/SIV approach. Indeed, Shi et al. have described a small-molecule inhibitor that prematurely uncoats the HIV-1 capsid core after viral entry [74]. While TRIM5 $\alpha$ restriction is clearly saturable and thus not an absolute block to infection, it can and does slow the spread of virus in target cells. Indeed, experiments in primary rhesus $\mathrm{CD} 4^{+} \mathrm{T}$ cells show that AgmTRIM5 $\alpha$ offers significant protection from SIV $_{\text {mac239 }}$ thereby enhancing their antiviral function (SJ, MTT, VIA, CO, and DEO manuscript submitted). Our results open up the SIV/rhesus macaque model for in vivo studies of TRIM $5 \alpha$ restriction. Of course, one consideration for using any xenogeneic TRIM $5 \alpha$ as a protective therapy is whether it will induce an adverse immune response in the recipient [8]. While this is likely to preclude the direct use of AgmTRIM5 $\alpha$ as a therapeutic, the nature of TRIM $5 \alpha$ is a facet of AIDS virus biology that is important to understand and potentially harness.

\section{Conclusions}

Using a dilution end-point replication assay, we find that AgmTRIM5 $\alpha$ exhibits a greater than $10^{3}$-fold level of restriction of HIV-1 and SIV $_{\text {mac239 }}$ replication in a transformed human $\mathrm{CD} 4^{+} \mathrm{T}$-cell line when expressed at near physiological levels. This level of restriction was markedly greater than the restriction observed in single-round or short term infectivity assays, indicating restriction building up cumulatively over many rounds of replication. Additionally, AgmTRIM5 $\alpha$ could restrict

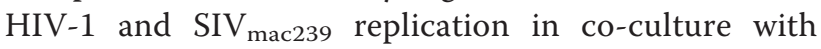
infected normal cells. In contrast, rhTRIM $5 \alpha$ failed to effectively restrict HIV-1 in co-culture, a finding previously observed for both rhTRIM5 $\alpha$ and a stabilized mutant human TRIM5 $\alpha$ exhibiting an extended halflife. Thus, AgmTRIM5 $\alpha$ is unique among the TRIM5 $\alpha$ proteins tested to date. These results provide a basis for directly examining TRIM5 $\alpha$ restriction in the SIV/ rhesus macaque model to better understand and potentially utilize this anti-AIDS virus mechanism in the clinic.

\section{Methods}

\section{Viruses and cells}

293T human embryonic kidney, Phoenix RD114 (clone 22) [75] and TZM-bl [76] (also known as JC53-BL clone 13) cells were cultured in Dulbecco's modified Eagle's medium supplemented with $2 \mathrm{mM}$ L-glutamine, $100 \mathrm{U}$ per ml penicillin, $100 \mu \mathrm{g}$ per $\mathrm{ml}$ streptomycin and $10 \%$ $\mathrm{vol} / \mathrm{vol}$ fetal bovine serum. Jurkat CCR5, Clone 4, and E11S cell lines were cultured in RPMI 1640 with the same supplements as those in the $293 \mathrm{~T}$ cell medium. All cell culture products were obtained from Life Technologies, Inc. All transient transfections of $293 \mathrm{~T}$ cells were carried out using TransIt293 (Mirus Bio Corp.). HIV-1, SIV mac239, and $\operatorname{SIV}_{\mathrm{Agm}}$ stocks were produced by transfecting HEK293T cells with pNL4-3 [77], p239 mac SPXL (gift of

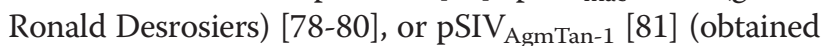
through the National Institutes of Health [NIH] AIDS Reagent Program, Division of AIDS, National Institute of Allergy and Infectious Diseases [NIAID], NIH, from Drs. Marcelo Soares and Beatrice Hahn). Viral and viral vector supernatants were passed through a $0.45 \mu$ filter before use. Short term infections were carried out in the presence of $2 \mu \mathrm{g} / \mathrm{mg}$ hexadimethrine bromide at an MOI of 0.05 .

\section{Retroviral vectors and generation of cell lines}

Agm- and gorTRIM5 $\alpha$ genes [22] were a kind gift of Theodora Hatziioannou (Aaron Diamond AIDS Research Center, New York, NY). The rhesus (rh) gene (Cat\# 10072) was obtained from the NIH AIDS Repository Program, Pathogenesis and Basic Research Branch, Division of AIDS, NIAID, Bethesda, MD). Agm-, gor-, and rhTRIM $5 \alpha$ genes were cloned into a modified MSCV PIG retroviral vector (obtained from Addgene, plasmid 18751, deposited by Scott Lowe) with an N-terminal hemagglutinin epitope tag (YPYDVPDYA) added to the TRIM5 $\alpha$ coding sequence to produce pSMS-Agm, pSMS-gor, and pSMS-rh vector constructs that also express both the puromycin resistance and GFP genes. The three TRIM $5 \alpha$ genes were also cloned into the pBabe-puro retroviral vector [82], obtained from Addgene, plasmid 1764, contributed by Bob Weinberg to produce pBabe-Agm, pBabe-gor, and pBabe-rh vector constructs. Retroviral vectors were packaged by transient transfection of Phoenix RD114 packaging cells [75] (kind gift of Hans-Peter Kleim, Fred Hutchinson Cancer Research Center, Seattle, WA). GFP-expressing JR5 cells were produced by transduction with a GAE-SFFV-GFP-WPRE lentiviral vector DNA (kind gift of Francois-Loic Cosset, Inserm Lyon, France) [83] that was modified by fusion of a P2A-puroTK cassette to the C-terminus of GPF to produce the GSPK vector that expresses GFP, and a puromycin-herpes thymidine kinase fusion gene. The GSPK lentiviral vector was produced by transiently cotransfecting HEK293T cells 
with the pGSPK DNA construct, and pAD-SIV4 packaging plasmid [83] (kind gift of F-L Cosset) and pLPVSVG, at a ratio of 4.5:4.1:1 by mass. GFP-expressing LKO HIV lentiviral vector (GE Healthcare Dharmacon, Piscataway, NJ) was packaged using the Virapower packaging system (Life Technologies) in transfected $293 \mathrm{~T}$ cells. Supernatants were collected $48 \mathrm{~h}$ post-transfection and passed through a $0.45 \mu$ filter. Transductions were carried out in the presence of $2 \mu \mathrm{g} / \mathrm{mg}$ hexadimethrine bromide and Viromag $\mathrm{R} / \mathrm{L}$ reagent (Boca Scientific, Inc.), the latter reagent concentrating supernatants to deliver a higher MOI. TRIM5 $\alpha$ vector transductants were selected for puromycin resistance. Puromycin (Sigma-Adlrich Inc.) selection was carried out at $2 \mu \mathrm{g} / \mathrm{ml}$. For single-round infectivity assays, transductions were carried out at an MOI of 0.05 .

\section{Virus and cell lysate preparation and isolation}

HIV-1-containing cell culture supernatants were clarified by centrifugation at $2,000 \times g$ for $5 \mathrm{~min}$ at $4^{\circ} \mathrm{C}$, and then samples directly lysed in a one-half volume of SDSPAGE loading buffer $(250 \mathrm{mM}$ Tris- $\mathrm{Cl} \mathrm{pH} 6.8,8 \%$ sodium dodecyl sulfate, $4 \% \mathrm{vol} / \mathrm{vol} \beta$-mercaptoethanol, $40 \% \mathrm{vol} / \mathrm{vol}$ glycerol, and $0.02 \%$ bromophenol brilliant blue). SIV-containing cell culture supernatants were clarified and then concentrated 10-fold using the Lenti-X virion concentration reagent (Clontech Laboratories) according to the manufacturer's instructions. Precipitated virions were lysed directly in SDS-PAGE gel loading buffer. Cell samples were collected and washed once with ice-cold Dulbecco's phosphate-buffered saline solution without $\mathrm{Ca}^{+2}$ or $\mathrm{Mg}^{+2}$ (D-PBS, Life Technologies) and then lysed with prechilled $10 \mathrm{mM}$ Tris $\mathrm{HCl} \mathrm{pH} \mathrm{7.5,} \mathrm{0.1 \%}$ SDS, $5 \mu \mathrm{g}$ of phenylmethanesulfonyl floride and $4 \mathrm{U} / \mu \mathrm{l}$ of Omnicleave ${ }^{\circ}$ nuclease (Epicentre Biotechnologies), incubated for $2 \mathrm{~h}$ at $4^{\circ} \mathrm{C}$ and treated with an equal volume of SDS-PAGE gel loading buffer.

\section{Near infrared (NIr) immunoblots}

Samples were separated by SDS-PAGE electrophoresis and blotted onto PVDF-FL membranes (Millipore) using a semi-dry apparatus as previously described [84]. Blots were blocked for at least $1 \mathrm{~h}$ in Odyssey blocking buffer (LI-COR Biosciences) and then incubated in blocking buffer with one or two primary antiserum (a)/antibody (ies) for at least $2 \mathrm{~h}$, typically overnight. Blots were washed twice with blocking buffer for $10 \mathrm{~m}$ then incubated with the appropriate donkey IRDye $800 \mathrm{CW}$ and/or IRDye680 LT fluorescently labeled secondary antibodies (LI-COR) at a 1:10,000 ratio vol/vol in blocking buffer for at least $2 \mathrm{~h}$. Blots were washed five times for 10 min each time in blocking buffer, and then analyzed with an Odyssey infrared imaging system (LI-COR) using a laser intensity of between 1 and 5. Signal densities of bands were measured by the Odyssey 3.0 application software. All blotting steps were carried out at room temperature. Monoclonal antibodies used were antirhTRIM5 $\alpha$, clone 3F1-1-9, (Cat\# 12271, NIH AIDS Reagent Program) and anti-beta actin (Cat\# 60008-1-Ig, ProteinTech Group). Primary goat antiserum against HIV p24 ${ }^{\mathrm{CA}} / \mathrm{SIV}$ p27 ${ }^{\mathrm{CA}}$ (goat \#81) was obtained from the AIDS and Cancer Virus Program, Frederick National Laboratory for Cancer Research , Frederick, MD.

\section{Virus release assays}

Virus release was carried out as previously described [85]. Briefly, $5 \times 10^{6}$ cells were collected by centrifugation, washed twice with PBS and then placed in $5 \mathrm{ml}$ of pre-warmed medium and incubated at $37^{\circ} \mathrm{C}$. At $6 \mathrm{~h}$, virus and cell lysates were prepared and analyzed by quantitative CA near infrared NIr immunoblot. Release factors for the viruses were determined by dividing the measured CA fluorescence values for the virus samples (arbitrary units) by the total Gag signal (virus + cellular Gag) to produce a release factor. The cellular Gag values were corrected for loading and cell extract processing differences by normalizing signals from actin staining with a second color.

\section{Specific infectivity assays}

Specific infectivity assays were carried out over a 6-h time period using the same procedure as the virus release assay presented above with clarified supernatants assayed for infectivity and virion lysate samples were prepared. Infectivity assays were performed using the TZM-bl single-round lacZ Tat complementation assay as previously described [86]. CA present in the supernatant was measured by CA NIr immunoblot. Specific infectivity was calculated dividing the virus titer by the CA band signal, expressed in blue cell-forming units per arbitrary CA fluorescence value. Heat inactivation was carried out at $70^{\circ} \mathrm{C}$ for $20 \mathrm{~min}$.

\section{Flow cytometry analysis of infected cell lines}

For each sample, medium containing $1-2 \times 10^{6}$ cells was centrifuged at $400 \times g$ for $5 \mathrm{~min}$ and fixed in $0.5 \mathrm{ml}$ of $4 \%$ $w t / v o l$ paraformaldehyde in D-PBS (Life Technologies) for $20 \mathrm{~min}$ at room temperature followed by the addition of $3.5 \mathrm{ml}$ permeabilization solution (PS), $0.1 \%$ (wt/vol) saponin (Sigma-Aldrich) in D-PBS, and incubation at room temperature for $10 \mathrm{~min}$. Cells were then collected by centrifugation at $550 \times g$ for $5 \mathrm{~min}$, followed by 2 washes with PS. Cells were then stained with KC57 antibody for HIV-1 CA (Beckman-Coulter, Inc.) or 2 F12 antibody for SIV CA (Quality Biological, Inc., Gaithersburg, MD) in $100 \mu \mathrm{l}$ of PS for $30 \mathrm{~min}$ in the dark at $4^{\circ} \mathrm{C}$, washed twice in $4 \mathrm{ml}$ of PS and then resuspended in $200 \mu \mathrm{l}$ of PS, and analyzed immediately by an LSRII flow cytometer (BD Biosciences) 
Data analysis was performed using FCS Express software (De Novo Software).

\section{Statistical analysis}

Single-round and short term infectivity data where analyzed using the Student's t-Test function in Excel (Microsoft Inc.) with paired two-tailed parameters.

\section{Ethical approval}

All research was carried out under approval by the NCI at Frederick Institutional Biosafety Committee \# 11-03 superseded by \#14-23.

\section{Competing interests}

The authors declare that they have on competing interests.

\section{Authors' contributions}

LVC produced the vector constructs and the immunoblots, MTT and VIA carried out flow cytometry analyses, SJ performed infectivity assays and some cell culture, GQDP contributed experimental design, CO contributed experimental design, data interpretation and manuscript assistance, DEO conceived and designed the study, produced cell lines, carried out infectivity and replication, complied data and wrote the manuscript. All authors read and approved the final manuscript.

\section{Acknowledgements}

We thank Theodora Hatziioannou for the African green monkey and gorilla TRIM5a genes, Hans-Peter Kleim for the Phoenix RD114 clone 22 packaging cell line, Francois-Loic Cosset for the GAE-SFFV-GFP-WPRE lentiviral vector DNA, and Rob Gorelick for helpful advice. The following reagents were obtained through the NIH AIDS Reagent Program, Division of AIDS, NIAID, $\mathrm{NIH}$ : Cat\# 12271 Anti-rhTRIM5a (3 F1-1-9), deposited by Tom Hope and Wes

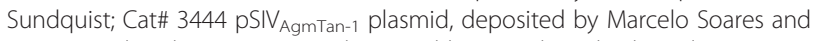
Beatrice Hahn; rhTRIM5a gene, deposited by Joseph Sodroski and Matt Stremlau; Cat\# 10072; 2 F12 SIV p27 hybridoma, Cat\#1547, deposited by Niels Pedersen. This project has been funded in whole or in part with federal funds from the National Cancer Institute, National Institutes of Health, under contract no. HHSN261200800001E. The content of this publication does not necessarily reflect the views or policies of the Department of Health and Human Services, nor does mention of trade names, commercial products, or organizations imply endorsement by the U.S. Government.

Received: 16 October 2014 Accepted: 8 January 2015

Published online: 07 February 2015

\section{References}

1. Greene WC, Debyser Z, Ikeda Y, Freed EO, Stephens E, Yonemoto W, et al. Novel targets for HIV therapy. Antiviral Res. 2008;80:251-65.

2. Anderson J, Akkina R. Human immunodeficiency virus type 1 restriction by human-rhesus chimeric tripartite motif 5alpha (TRIM 5alpha) in CD34(+) cell-derived macrophages in vitro and in T cells in vivo in severe combined immunodeficient (SCID-hu) mice transplanted with human fetal tissue. Hum Gene Ther. 2008;19:217-28.

3. Anderson JS. Using TRIM5alpha as an HIV therapeutic: the alpha gene? Expert Opin Biol Ther. 2013;13:1029-38.

4. Chan E, Towers GJ, Qasim W. Gene therapy strategies to exploit TRIM derived restriction factors against HIV-1. Viruses. 2014;6:243-63.

5. Sloan RD, Wainberg MA. Harnessing the therapeutic potential of host antiviral restriction factors that target HIV. Expert Rev Anti Infect Ther. 2013;11:1-4.

6. Zhang J, Ge W, Zhan P, De Clercq E, Liu X. Retroviral restriction factors TRIM5alpha: therapeutic strategy to inhibit HIV-1 replication. Curr Med Chem. 2011;18:2649-54.

7. Nakayama EE, Shioda T. Anti-retroviral activity of TRIM5 alpha. Rev Med Virol. 2010:20:77-92.

8. Neagu MR, Ziegler P, Pertel T, Strambio-De-Castillia C, Grutter C, Martinetti $\mathrm{G}$, et al. Potent inhibition of HIV-1 by TRIM5-cyclophilin fusion proteins engineered from human components. J Clin Invest. 2009;119:3035-47.
9. Stremlau M, Perron M, Welikala S, Sodroski J. Species-specific variation in the B30.2(SPRY) domain of TRIM5alpha determines the potency of human immunodeficiency virus restriction. J Virol. 2005;79:3139-45.

10. Richardson MW, Guo L, Xin F, Yang X, Riley JL. Stabilized human TRIM5alpha protects human T cells from HIV-1 infection. Mol Ther. 2014;22:1084-95.

11. Malim MH, Bieniasz PD. HIV Restriction Factors and Mechanisms of Evasion. Cold Spring Harb Perspect Med. 2012;2:a006940.

12. Reymond A, Meroni G, Fantozzi A, Merla G, Cairo S, Luzi L, et al. The tripartite motif family identifies cell compartments. EMBO J. 2001;20:2140-51.

13. Li X, Gold B, O'HUigin C, Diaz-Griffero F, Song B, Si Z, et al. Unique features of TRIM5alpha among closely related human TRIM family members. Virology. 2007;360:419-33.

14. Sastri J, Campbell EM. Recent insights into the mechanism and consequences of TRIM5alpha retroviral restriction. AIDS Res Hum Retroviruses. 2011;27:231-8.

15. Gartner S, Liu Y, Polonis V, Lewis MG, Elkins WR, Hunter EA, et al. Adaptation of HIV-1 to pigtailed macaques. J Med Primatol. 1994;23:155-63.

16. Himathongkham S, Luciw PA. Restriction of HIV-1 (subtype B) replication at the entry step in rhesus macaque cells. Virology. 1996;219:485-8.

17. Shibata R, Kawamura M, Sakai H, Hayami M, Ishimoto A, Adachi A. Generation of a chimeric human and simian immunodeficiency virus infectious to monkey peripheral blood mononuclear cells. J Virol. 1991;65:3514-20.

18. Stremlau M, Owens CM, Perron MJ, Kiessling M, Autissier P, Sodroski J. The cytoplasmic body component TRIM5alpha restricts HIV-1 infection in Old World monkeys. Nature. 2004;427:848-53.

19. Owens CM, Song B, Perron MJ, Yang PC, Stremlau M, Sodroski J. Binding and susceptibility to postentry restriction factors in monkey cells are specified by distinct regions of the human immunodeficiency virus type 1 capsid. J Virol. 2004;78:5423-37.

20. Zhang F, Perez-Caballero D, Hatziioannou T, Bieniasz PD. No effect of endogenous TRIM5alpha on HIV-1 production. Nat Med. 2008;14:235-6. author reply 236-238.

21. Hatziioannou T, Perez-Caballero D, Yang A, Cowan S, Bieniasz PD. Retrovirus resistance factors Ref1 and LV1 are species-specific variants of TRIM5alpha. Proc Natl Acad Sci U S A. 2004;101:10774-9.

22. Kratovac Z, Virgen CA, Bibollet-Ruche F, Hahn BH, Bieniasz PD, Hatziioannou T. Primate lentivirus capsid sensitivity to TRIM5 proteins. J Virol. 2008;82:6772-7.

23. Keckesova Z, Ylinen LM, Towers GJ. The human and African green monkey TRIM5alpha genes encode Ref1 and LV1 retroviral restriction factor activities. Proc Natl Acad Sci U S A. 2004;101:10780-5.

24. Song B, Javanbakht H, Perron M, Park DH, Stremlau M, Sodroski J. Retrovirus restriction by TRIM5alpha variants from Old World and New World primates. J Virol. 2005;79:3930-7.

25. Goldschmidt V, Ciuffi A, Ortiz M, Brawand D, Munoz M, Kaessmann H, et al. Antiretroviral activity of ancestral TRIM5alpha. J Virol. 2008;82:2089-96.

26. Yap MW, Nisole S, Lynch C, Stoye JP. Trim5alpha protein restricts both HIV-1 and murine leukemia virus. Proc Natl Acad Sci U S A. 2004;101:10786-91.

27. Yap MW, Nisole S, Stoye JP. A single amino acid change in the SPRY domain of human Trim5alpha leads to HIV-1 restriction. Curr Biol. 2005;15:73-8.

28. Sawyer SL, Wu LI, Emerman M, Malik HS. Positive selection of primate TRIM5alpha identifies a critical species-specific retroviral restriction domain. Proc Natl Acad Sci U S A. 2005;102:2832-7.

29. Perez-Caballero D, Hatziioannou T, Yang A, Cowan S, Bieniasz PD. Human tripartite motif 5 alpha domains responsible for retrovirus restriction activity and specificity. J Virol. 2005;79:8969-78.

30. Nakayama EE, Miyoshi H, Nagai Y, Shioda T. A specific region of 37 amino acid residues in the SPRY (B30.2) domain of African green monkey TRIM5alpha determines species-specific restriction of simian immunodeficiency virus SIVmac infection. J Virol. 2005;79:8870-7.

31. Maegawa H, Miyamoto T, Sakuragi J, Shioda T, Nakayama EE. Contribution of RING domain to retrovirus restriction by TRIM5alpha depends on combination of host and virus. Virology. 2010;399:212-20.

32. Kim J, Tipper C, Sodroski J. Role of TRIM5alpha RING domain E3 ubiquitin ligase activity in capsid disassembly, reverse transcription blockade, and restriction of simian immunodeficiency virus. J Virol. 2011;85:8116-32.

33. Javanbakht H, Diaz-Griffero F, Stremlau M, Si Z, Sodroski J. The contribution of RING and B-box 2 domains to retroviral restriction mediated by monkey TRIM5alpha. J Biol Chem. 2005;280:26933-40. 
34. Diaz-Griffero F, Kar A, Lee M, Stremlau M, Poeschla E, Sodroski J. Comparative requirements for the restriction of retrovirus infection by TRIM5alpha and TRIMCyp. Virology. 2007;369:400-10.

35. Kutluay SB, Perez-Caballero D, Bieniasz PD. Fates of retroviral core components during unrestricted and TRIM5-restricted infection. PLoS Pathog. 2013;9:e1003214

36. Wu X, Anderson JL, Campbell EM, Joseph AM, Hope TJ. Proteasome inhibitors uncouple rhesus TRIM5alpha restriction of HIV-1 reverse transcription and infection. Proc Natl Acad Sci U S A. 2006;103:7465-70.

37. Perez-Caballero D, Hatziioannou T, Zhang F, Cowan S, Bieniasz PD. Restriction of human immunodeficiency virus type 1 by TRIM-CypA occurs with rapid kinetics and independently of cytoplasmic bodies, ubiquitin, and proteasome activity. J Virol. 2005;79:15567-72.

38. Sundquist WI, Krausslich HG. HIV-1 assembly, budding, and maturation. Cold Spring Harb Perspect Med. 2012;2:a006924.

39. von Schwedler UK, Stray KM, Garrus JE, Sundquist WI. Functional surfaces of the human immunodeficiency virus type 1 capsid protein. J Virol. 2003;77:5439-50.

40. Forshey BM, von Schwedler U, Sundquist WI, Aiken C. Formation of a human immunodeficiency virus type 1 core of optimal stability is crucial for viral replication. J Virol. 2002;76:5667-77.

41. Ganser-Pornillos BK, Chandrasekaran V, Pornillos O, Sodroski JG, Sundquist WI, Yeager M. Hexagonal assembly of a restricting TRIM5alpha protein. Proc Natl Acad Sci U S A. 2011;108:534-9.

42. Shi J, Friedman DB, Aiken C. Retrovirus restriction by TRIM5 proteins requires recognition of only a small fraction of viral capsid subunits. J Virol. 2013;87:9271-8

43. Stremlau M, Perron M, Lee M, Li Y, Song B, Javanbakht $H$, et al. Specific recognition and accelerated uncoating of retroviral capsids by the TRIM5alpha restriction factor. Proc Natl Acad Sci U S A. 2006;103:5514-9.

44. Perron MJ, Stremlau M, Lee M, Javanbakht H, Song B, Sodroski J. The human TRIM5alpha restriction factor mediates accelerated uncoating of the N-tropic murine leukemia virus capsid. J Virol. 2007;81:2138-48.

45. Roa A, Hayashi F, Yang Y, Lienlaf M, Zhou J, Shi J, et al. RING domain mutations uncouple TRIM5alpha restriction of HIV-1 from inhibition of reverse transcription and acceleration of uncoating. J Virol. 2012:86:1717-27.

46. Danielson CM, Cianci GC, Hope TJ. Recruitment and dynamics of proteasome association with rhTRIM5alpha cytoplasmic complexes during HIV-1 infection. Traffic. 2012;13:1206-17.

47. Pertel T, Hausmann S, Morger D, Zuger S, Guerra J, Lascano J, et al. TRIM5 is an innate immune sensor for the retrovirus capsid lattice. Nature. 2011:472:361-5.

48. Richardson MW, Carroll RG, Stremlau M, Korokhov N, Humeau LM, Silvestri $G$, et al. Mode of transmission affects the sensitivity of human immunodeficiency virus type 1 to restriction by rhesus TRIM5alpha. J Virol. 2008;82:11117-28.

49. Sakuma R, Noser JA, Ohmine S, Ikeda Y. Inhibition of HIV-1 replication by simian restriction factors, TRIM5alpha and APOBEC3G. Gene Ther. 2007;14:185-9.

50. Hatziioannou T, Evans DT. Animal models for HIV/AIDS research. Nat Rev Microbiol. 2012;10:852-67.

51. Ohmine S, Sakuma R, Sakuma T, Thatava T, Takeuchi H, Ikeda Y. The antiviral spectra of TRIM5alpha orthologues and human TRIM family proteins against lentiviral production. PLoS One. 2011;6:e16121.

52. Uchil PD, Quinlan BD, Chan WT, Luna JM, Mothes W. TRIM E3 ligases interfere with early and late stages of the retroviral life cycle. PLoS Pathog. 2008;4:e16.

53. Gousset K, Ablan SD, Coren LV, Ono A, Soheilian F, Nagashima K, et al. Real-time visualization of HIV-1 Gag trafficking in infected macrophages. PLoS Pathog. 2008:4:e1000015.

54. Pearce-Pratt R, Malamud D, Phillips DM. Role of the cytoskeleton in cell-to-cell transmission of human immunodeficiency virus. J Virol. 1994;68:2898-905.

55. Sattentau QJ. The direct passage of animal viruses between cells. Curr Opin Virol. 2011;1:396-402

56. Dimitrov DS, Willey RL, Sato H, Chang L-J, Blumenthal R, Martin MA. Quantitation of human immunodeficiency virus type 1 infection kinetics. J Virol. 1993:67:2182-90.

57. Carr JM, Hocking H, Li P, Burrell CJ. Rapid and efficient cell-to-cell transmission of human immunodeficiency virus infection from monocyte-derived macrophages to peripheral blood lymphocytes. Virology. 1999;265:319-29.
58. Chen P, Hubner W, Spinelli MA, Chen BK. Predominant mode of human immunodeficiency virus transfer between T cells is mediated by sustained Env-dependent neutralization-resistant virological synapses. J Virol. 2007:81:12582-95.

59. Sourisseau M, Sol-Foulon N, Porrot F, Blanchet F, Schwartz O. Inefficient human immunodeficiency virus replication in mobile lymphocytes. J Virol. 2007:81:1000-12

60. Zhong P, Agosto LM, llinskaya A, Dorjbal B, Truong R, Derse D, et al. Cell-to-cell transmission can overcome multiple donor and target cell barriers imposed on cell-free HIV. PLoS One. 2013;8:e53138.

61. Martin N, Welsch S, Jolly C, Briggs JA, Vaux D, Sattentau QJ. Virological synapse-mediated spread of human immunodeficiency virus type 1 between T cells is sensitive to entry inhibition. J Virol. 2010;84:3516-27.

62. Sakuma R, Noser JA, Ohmine S, Ikeda Y. Rhesus monkey TRIM5alpha restricts HIV-1 production through rapid degradation of viral Gag polyproteins. Nat Med. 2007;13:631-5.

63. Sakuma R, Ohmine S, Mael AA, Noser JA, Ikeda Y. Author reply to comment on Rhesus monkey TRIM5alpha restricts HIV-1 production through rapid degradation of viral Gag polyproteins. Nat Med. 2008;14:235-6.

64. Ott DE, Nigida Jr SM, Henderson LE, Arthur LO. The majority of cells are superinfected in a cloned cell line that produces high levels of human immunodeficiency virus type 1 strain MN. J Virol. 1995;69:2443-50.

65. Benveniste RE, Hill RW, Eron $\sqcup$, Csaikl UM, Knott WB, Henderson LE, et al. Characterization of clones of HIV-1 infected HuT 78 cells defective in gag gene processing and of SIV clones producing large amounts of envelope glycoprotein. J Med Primatol. 1990;19:351-66.

66. Ohkura S, Goldstone DC, Yap MW, Holden-Dye K, Taylor IA, Stoye JP. Novel escape mutants suggest an extensive TRIM5alpha binding site spanning the entire outer surface of the murine leukemia virus capsid protein. PLoS Pathog. 2011;7:e1002011.

67. Ohkura S, Stoye JP. A comparison of murine leukemia viruses that escape from human and rhesus macaque TRIM5alphas. J Virol. 2013;87:6455-68.

68. Shi J, Aiken C. Saturation of TRIM5 alpha-mediated restriction of HIV-1 infection depends on the stability of the incoming viral capsid. Virology. 2006:350:493-500.

69. Hatziioannou T, Cowan S, Goff SP, Bieniasz PD, Towers GJ. Restriction of multiple divergent retroviruses by LV1 and Ref1. EMBO J. 2003;22:385-94.

70. Besnier C, Takeuchi Y, Towers G. Restriction of lentivirus in monkeys. Proc Natl Acad Sci U S A. 2002;99:11920-5.

71. Cowan S, Hatziioannou T, Cunningham T, Muesing MA, Gottlinger HG, Bieniasz PD. Cellular inhibitors with Fv1-like activity restrict human and simian immunodeficiency virus tropism. Proc Natl Acad Sci U S A. 2002;99:11914-9.

72. Layne SP, Merges MJ, Dembo M, Spouge JL, Conley SR, Moore JP, et al. Factors underlying spontaneous inactivation and susceptibility to neutralization of human immunodeficiency virus. Virology. 1992;189:695-714.

73. Zhang B, Metharom P, Jullie H, Ellem KA, Cleghorn G, West MJ, et al. The significance of controlled conditions in lentiviral vector titration and in the use of multiplicity of infection (MOI) for predicting gene transfer events. Genet Vaccines Ther. 2004;2:6.

74. Shi J, Zhou J, Shah VB, Aiken C, Whitby K. Small-molecule inhibition of human immunodeficiency virus type 1 infection by virus capsid destabilization. J Virol. 2010;85:542-9.

75. Neff T, Peterson LJ, Morris JC, Thompson J, Zhang X, Horn PA, et al. Efficient gene transfer to hematopoietic repopulating cells using concentrated RD114-pseudotype vectors produced by human packaging cells. Mol Ther. 2004:9:157-9.

76. Wei X, Decker JM, Liu H, Zhang Z, Arani RB, Kilby JM, et al. Emergence of resistant human immunodeficiency virus type 1 in patients receiving fusion inhibitor (T-20) monotherapy. Antimicrob Agents Chemother. 2002;46:1896-905.

77. Adachi A, Koenig S, Gendelman HE, Daugherty D, Gattoni-Celli S, Fauci AS, et al. Productive, persistent infection of human colorectal cell lines with human immunodeficiency virus. J Virol. 1987;61:209-13.

78. Kestler H, Kodama T, Ringler D, Marthas M, Pedersen N, Lackner A, et al. Induction of AIDS in rhesus monkeys by molecularly cloned simian immunodeficiency virus. Science. 1990;248:1109-12.

79. Kestler 3rd HW, Ringler DJ, Mori K, Panicali DL, Sehgal PK, Daniel MD, et al. Importance of the nef gene for maintenance of high virus loads and for development of AIDS. Cell. 1991;65:651-62.

80. Minang JT, Trivett MT, Coren LV, Barsov EV, Piatak Jr M, Ott DE, et al. Nef-mediated MHC class I down-regulation unmasks clonal differences in 
virus suppression by SIV-specific CD8 ${ }^{+} \mathrm{T}$ cells independent of IFN-gamma and CD107a responses. Virology. 2009;391:130-9.

81. Soares MA, Robertson DL, Hui H, Allan JS, Shaw GM, Hahn BH. A full-length and replication-competent proviral clone of SIVAGM from tantalus monkeys. Virology. 1997;228:394-9.

82. Morgenstern JP, Land H. A series of mammalian expression vectors and characterisation of their expression of a reporter gene in stably and transiently transfected cells. Nucleic Acids Res. 1990;18:1068.

83. Negre $D$, Mangeot $P E$, Duisit $G$, Blanchard $S$, Vidalain $P O$, Leissner $P$, et al. Characterization of novel safe lentiviral vectors derived from simian immunodeficiency virus (SIVmac251) that efficiently transduce mature human dendritic cells. Gene Ther. 2000;7:1613-23.

84. Ott DE, Chertova EN, Busch LK, Coren LV, Gagliardi TD, Johnson DG. Mutational analysis of the hydrophobic tail of the human immunodeficiency virus type $1 \mathrm{p6}(\mathrm{Gag})$ protein produces a mutant that fails to package its envelope protein. J Virol. 1999;73:19-28.

85. Ott DE, Coren LV, Sowder II RC, Adams J, Nagashima K, Schubert U. Equine infectious anemia virus and the ubiquitin-proteasome system. J Virol. 2002;76:3038-44.

86. Vazquez N, Greenwell-Wild T, Marinos NJ, Swaim WD, Nares S, Ott DE, et al. Human immunodeficiency virus type 1-induced macrophage gene expression includes the p21 gene, a target for viral regulation. J Virol. 2005;79:4479-91.

\section{Submit your next manuscript to BioMed Central and take full advantage of:}

- Convenient online submission

- Thorough peer review

- No space constraints or color figure charges

- Immediate publication on acceptance

- Inclusion in PubMed, CAS, Scopus and Google Scholar

- Research which is freely available for redistribution 